\title{
Study of an UWB Spherical Monopole Antenna on the Dielectric Substrate
}

\author{
Seyed Ehsan Hosseini and Mostafa Attaran Kakhki
}

\begin{abstract}
A spherical monopole antenna on the dielectric substrate is proposed for UWB applications. The antenna uses a combination of the conductor spherical antenna, the dielectric substrate and the ground plane under substrate. The simulated results demonstrate that the design structure covers the frequency range $4.6 \mathrm{GHz}-10.6 \mathrm{GHz}$ and more. The radius of sphere and the height of the antenna is $R=5 \mathrm{~mm}, \mathrm{~h}=3.2 \mathrm{~mm}$, respectively. In this paper, the effects of varying the dielectric constant, the radius of spherical, and the height are investigated. Good radiations are obtained over the wide bandwidth with an acceptable gain. Also, the input impedance of the proposed antenna is simulated by HFSS and demonstrated. Details of design structure are presented and studied.
\end{abstract}

Index Terms-Spherical antennas, monopole antennas, UWB.

\section{INTRODUCTION}

In recent years, UWB antenna designing has been interested to be applied in short-range and high speed transmission signals. The technology of ultra-wideband (UWB) was allocated a bandwidth of 7.5 GHz (3.1-10.6 GHz) by the Federal Communication Commission (FCC) [1]. Several antenna structures were introduced for UWB technology. The history of broadband antenna was investigated in [2]. Dipole and monopole spherical and ellipsoidal antennas were proposed for broadband applications by Stohr [3]. Since the spherical antennas are substantially different from well-known designs, explaining their broadband behaviour is hard. One type of UWB antennas is spherical monopole antenna. The spherical antenna patent is presented in [4] that consist of a sphere, disk and coaxial cable. Various interesting spherical antenna designs are reported in the literatures [5]-[7]. In this letter, we propose a new spherical monopole antenna on the dielectric substrate that the ground plane is located under substrate. The feed of line in this antenna is $50-\Omega$ coaxial cable. This antenna exhibit good impedance matching over the very large frequency range. In this antenna, the omni-directional and sufficient gain characteristics that are essential for UWB applications, are obtained. The article is organized as fellows. In the next section, we described geometry and design of the proposed antenna. The simulation results for different dimensions of the proposed antenna are given in section III. Finally, the paper is concluded in section IV.

Manuscript received October 13, 2012; revised November 28, 2012.

The authors are with Electrical Department of Ferdowsi University of Mashhad, Mashhad, Iran (e-mail: m.attarankakhki@ieee.org).

\section{ANTENNA DEsign StRUCTURE}

The antenna geometry is shown in Fig. 1. The radius of sphere is $\mathrm{R}=5 \mathrm{~mm}$. The spherical antenna must be mounted at the centre of 3.2-mm-thick FR4 substrate of length $30 \mathrm{~mm}$ and width $30 \mathrm{~mm}$. The FR4 substrate has a relative permittivity 4.4 and a loss tangent 0.0245 . In this study, the spherical antenna is connected to central conductor of $50-\Omega$ coaxial line and its outer grounding sheath is connected to the ground plane.

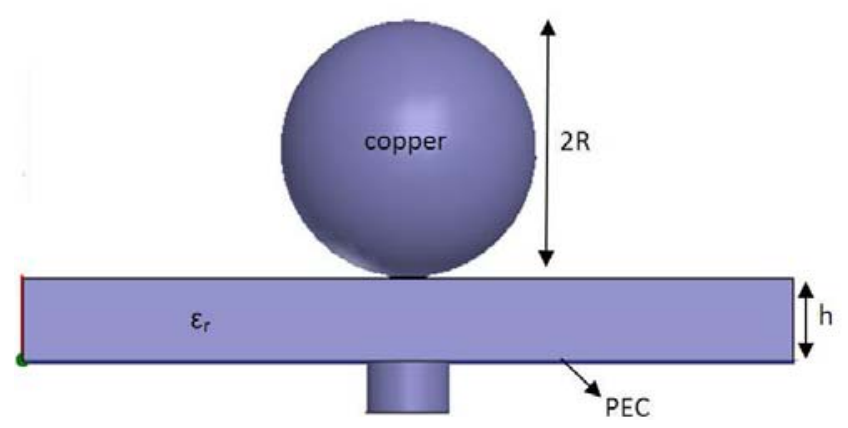

(a)

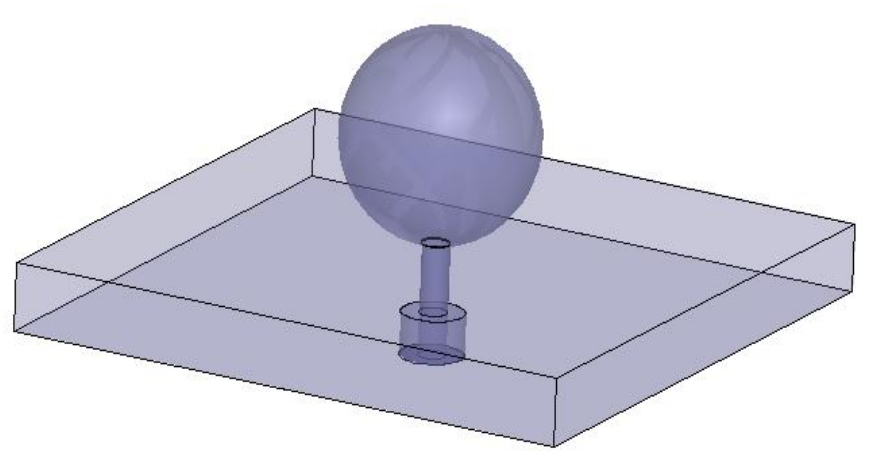

(b)

Fig. 1. Geometry of the spherical antenna with design parameters (a) Cross section (b) 3-D view

\section{RESUlTS AND DISCUSSION}

The proposed antenna structure was simulated and optimized using Ansoft High Frequency Structure Simulator (HFSS) using the finite element analysis method [8].

Fig. 2 shows the simulated return losses of the proposed spherical antenna on the different dielectric substrates. The effects of the various substrates with different dielectric constants are studied. It is seen that the broadband property of the antenna is lost with increasing the dielectric constant. The proposed antenna is resonated at several resonance frequencies, when a substrate is applied with high dielectric constant. For example, when the dielectric with $\varepsilon_{\mathrm{r}}=10$ is used as substrate, five resonant frequencies are excited in range 


\section{2-12 GHz.}

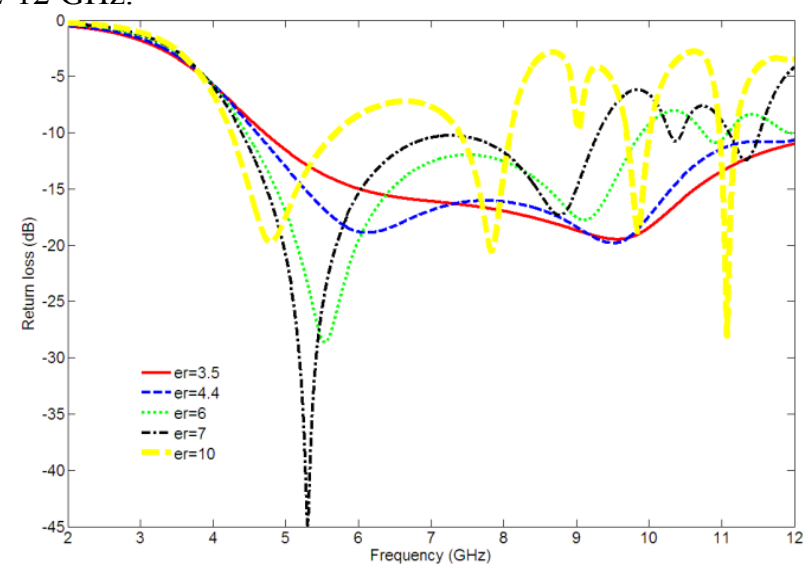

Fig. 2. Return losses for substrates with various dielectric constants

In order to increasing the bandwidth of the proposed antenna, the radius of sphere has been increased. The increasing of radius lengthens the current path on the spherical antenna. The simulated return losses are shown in Fig. 3. It is observed, increasing the radius of sphere from $\mathrm{R}=3 \mathrm{~mm}$ to $\mathrm{R}=5 \mathrm{~mm}$ and $\mathrm{R}=7 \mathrm{~mm}$, the bandwidths are increased about $1.85 \mathrm{GHz}$ and $2.7 \mathrm{GHz}$, respectively.

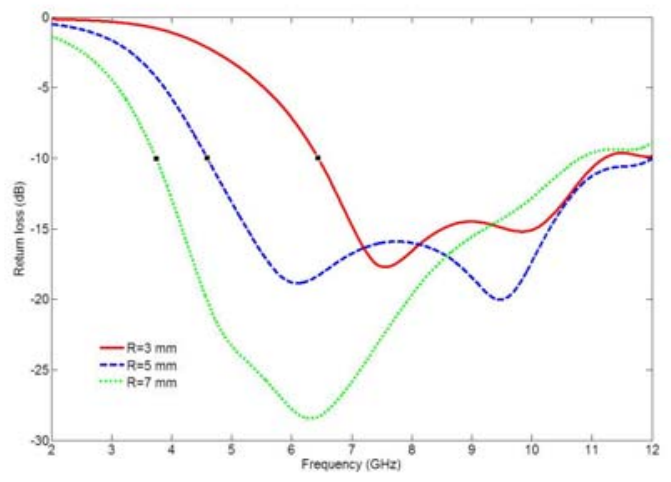

Fig. 3. Return losses for various spherical radiuses

Fig. 4 shows the simulated return losses of the proposed spherical monopole antenna with the varying of the height from $\mathrm{h}=0.8 \mathrm{~mm}$ to $\mathrm{h}=4.8 \mathrm{~mm}$ with $0.8 \mathrm{~mm}$ steps. The simulated results clearly indicate that increasing $\mathrm{h}$ parameter causes impedance matching improvement until $\mathrm{h}=3.2 \mathrm{~mm}$, but for further amount of $\mathrm{h}$, the mentioned impedance matching is decreased. Having the widest bandwidth, $h=3.2$ $\mathrm{mm}$ is the best result for this parameter's sweep.

As it has been mentioned, increasing the dielectric constant to $\varepsilon_{\mathrm{r}}=10$, the spherical antenna will be exited at five resonance frequencies. The simulated return loss for $\varepsilon_{\mathrm{r}}=10$ is shown in Fig. 5. The simulated resonance frequencies are 4.72, 7.8, 9.04, 9.68 and $11.09 \mathrm{GHz}$ with simulated return losses $-19,-20,-9,-10,-25 \mathrm{~dB}$ and their impedance bandwidths are $29 \%, 8 \%, 0,3.2 \%, 1.8 \%$ for return loss $\mathrm{S}_{11}$ less than or equal to $-10 \mathrm{~dB}$,respectively. The radiation patterns at three frequency of the proposed spherical monopole antenna are shown in Fig. 6. The radiation patterns for the spherical antenna with $\varepsilon_{\mathrm{r}}=10$ at resonance frequencies are simulated and shown in Fig 7. As it is observed, the radiation patterns in $\mathrm{x}-\mathrm{z}$ plane and $\mathrm{y}-\mathrm{z}$ plane are the same, because the structure of the spherical antenna is symmetrical.

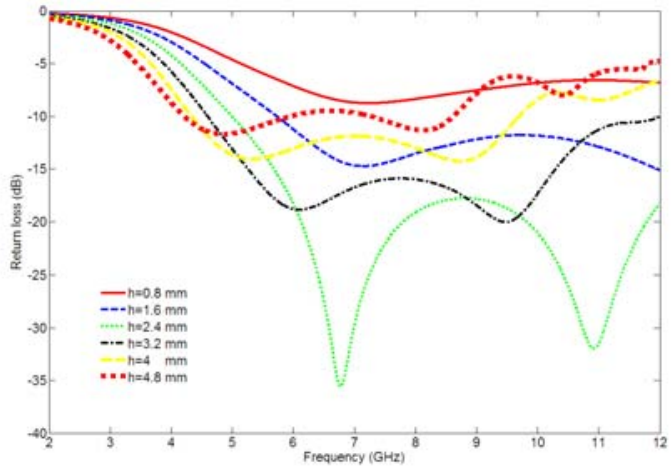

Fig. 4. Return losses for substrates with various heights

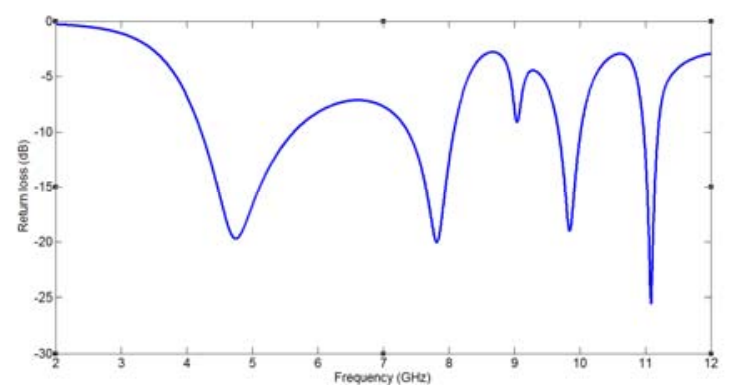

Fig. 5. Return loss for the spherical antenna with $\varepsilon_{\mathrm{r}}=10, \mathrm{~h}=3.2 \mathrm{~mm}, \mathrm{R}=5$ $\mathrm{mm}$

Fig. 8 shows the simulated input impedance of the spherical monopole antenna versus frequency. As shown in Fig. 8, the input impedance of the antenna is about $40 \Omega$ that its impedance performance is invariable if the antenna dimensions remain unchanged. In other words, frequency-independent behavior for input impedance property at frequencies above $7.7 \mathrm{GHz}$ in this antenna is obtained.

\section{CONCLUSION}

A new spherical monopole antenna that is suitable for UWB applications has been proposed. The spherical antenna that is mounted on the dielectric substrate has simple configuration and it is fed by coaxial cable. The return losses have been simulated for different parameters sweep. The effects of changing parameters for the proposed antenna have been investigated. Good radiation patterns for frequencies at the operating bands have been achieved. Since the antenna structure is completely symmetrical, the $\mathrm{XZ}$ plane and the $\mathrm{YZ}$ plane results are completely overlapped. Also, we observed frequency independent behavior for the proposed spherical monopole antenna on the dielectric.

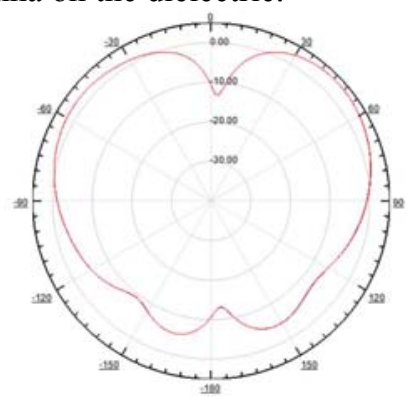

(a) 


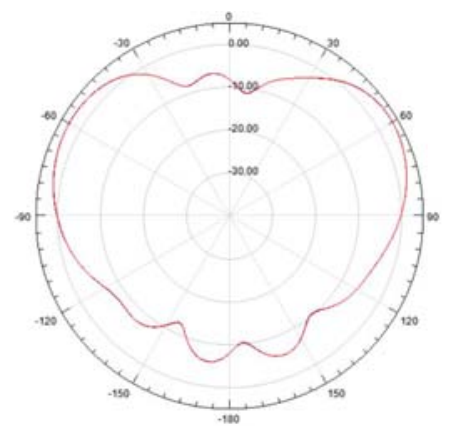

(b)

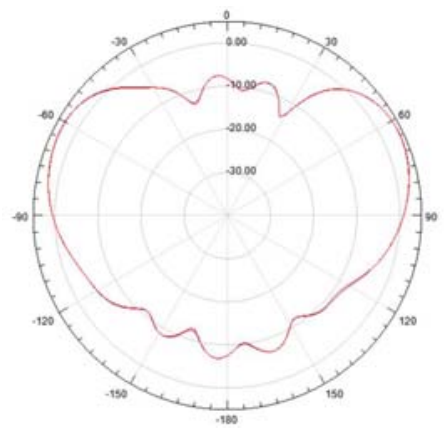

(c)

Fig. 6. Simulated radiation patterns for the proposed spherical monopole antenna with $\varepsilon_{\mathrm{r}}=4.4, \mathrm{~h}=3.2 \mathrm{~mm}, \mathrm{R}=5 \mathrm{~mm}[\mathrm{XZ}$ plane $(\mathrm{phi}=0)$ and $\mathrm{YZ}$ plane (phi=90) are the same and overlap]

(a) $5.25 \mathrm{GHz}$ (b) $7.25 \mathrm{GHz}$ (c) $9.25 \mathrm{GHz}$

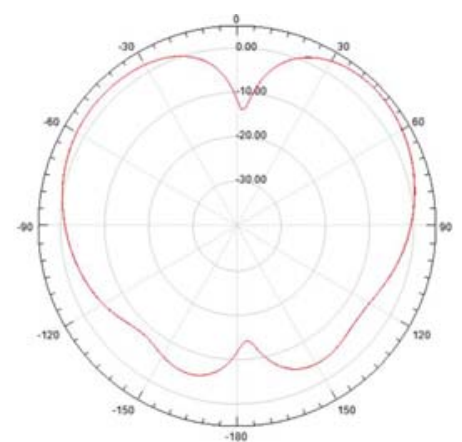

(a)

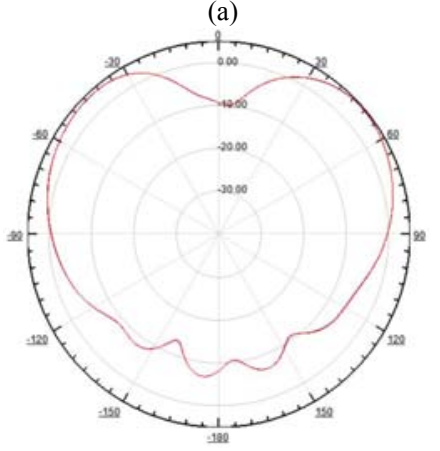

(b)

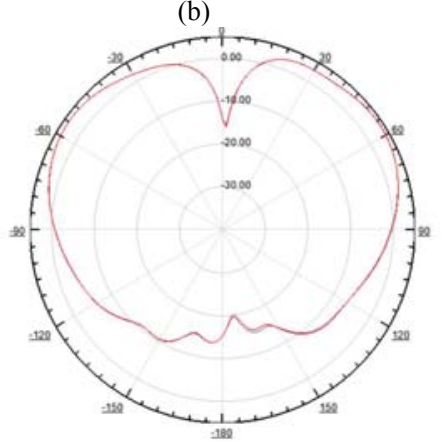

(c)

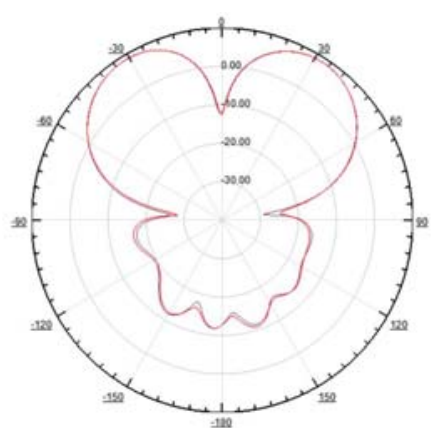

(d)

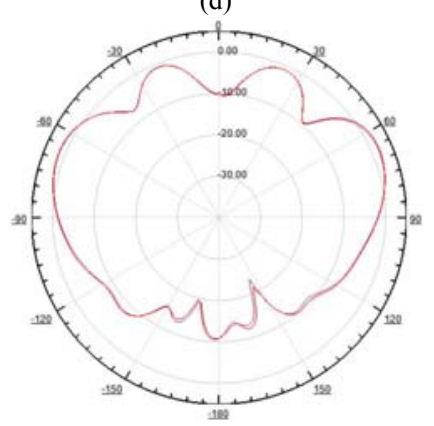

(e)

Fig. 7. Simulated radiation patterns for the proposed spherical monopole antenna with $\varepsilon_{\mathrm{r}}=10, \mathrm{~h}=3.2 \mathrm{~mm}, \mathrm{R}=5 \mathrm{~mm},[\mathrm{XZ}$ plane $(\mathrm{phi}=0)$ and $\mathrm{YZ}$ plane $(\mathrm{phi}=90)$ are the same and overlap]

(a) $4.72 \mathrm{GHz}$ (b) $7.8 \mathrm{GHz}$ (c) $9.04 \mathrm{GHz}$ (d) $9.68 \mathrm{GHz}$ (e) $11.09 \mathrm{GHz}$

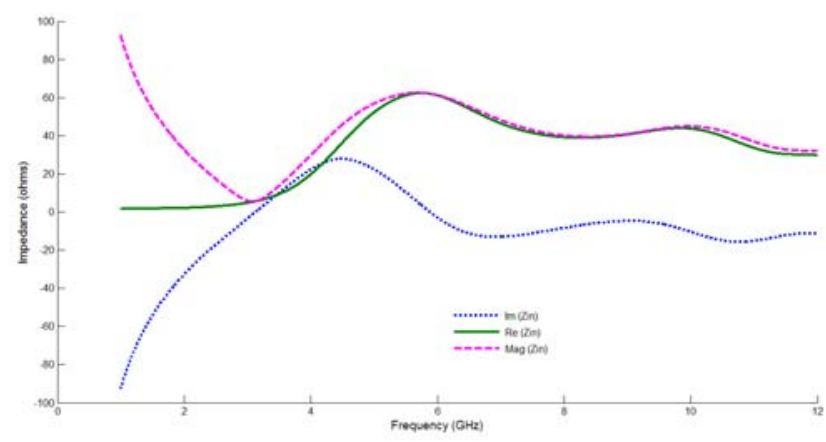

Fig. 8. Simulated input impedance of the spherical monopole antenna versus frequency

\section{ACKNOWLEDGMENT}

The authors would like to thank Iran Telecommunication Research Center (ITRC) for the financial support of this project. The authors would like to thank Mr. A. Pourzadi for his helpful review on initial manuscript.

\section{REFERENCES}

[1] Federal Communications Commission, Washington, DC, "FCC report and order on ultra wideband technology," 2002.

[2] H. G. Schantz, "A brief history of UWB antennas," IEEE Aerosp and Electron. Syst. Mag., vol. 19, no. 4, pp.22-26, April 2004.

[3] W. Stohr, "Broadband ellipsoidal dipole antenna," U.S. Patent 3, pp. 364-491, Jan. 161968.

[4] K. Shibata, "antenna," JP Patent 3831141, Oct. 11, 2006.

[5] T. Suzuki, S. Theerawisitpong, and Y. Watanabe, "Prospect of 40-170 $\mathrm{GHz}$ band spherical antenna," International Conference on Terahertz Electronics, IRMMW-THz, pp. 803-804, 2007.

[6] G. H. Huff and J. J. Mcdonald, "A spherical inverted-F antenna (SIFA)," IEEE Antenna Wireless Propag. Lett, vol. 8, pp. 649 652 ,May. 2009.

[7] A. Mehdipour, K. M. Aghdam, and R. F. Dana, "A novel spherical bifurcated UWB antenna for ultra wideband communication," Eu CAP the second European Conference, pp. 1-6, November 2007.

[8] Ansoft corp. HFSS. [Online]. Available: http://www.ansoft.com/products/hf/hfss. 


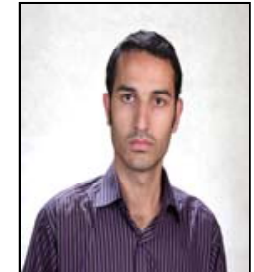

Seyed Ehsan Hosseini was born in Kerman, Iran, in 1987. He received the B.Sc. degree from Shahid Bahonar University of Kerman, Iran, in 2008 and the M.S. degree in electrical engineering from Ferdows University of Mashhad, in 2011. From 2009 to 2011, he was with the Computer and Communications Research Center (C\&C), Ferdowsi University of Mashhad, as antenna designer and researcher. His current research interests include antenna theory and design, multiband planar antennas for handsets, and UWB antennas.

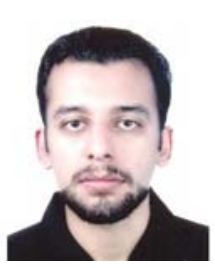

Mostafa Attaran Kakhki was born in Mashhad, Iran, in 1984. He received the B.Sc. degree in electrical engineering from Islamic Azad University of Central Tehran Branch (IAUCTB) and his M.Sc. degree of electrical engineering at Ferdowsi University of Mashhad, Mashhad, Iran. His research interests are image processing, Genetic Algorithm, microstripe antennas and filters, and DGS structures. 